\title{
Paulo Bruscky: Intervenções e Deslocamentos de Sentido no Espaço Urbano
}

\author{
Paulo Bruscky: Interventions and Displacements of Sense \\ at the Urban Space
}

por Pamella Emília Queiroz Araújo

RESUMO

Paulo Bruscky é um artista brasileiro reconhecido internacionalmente pela sua ampla produção intermídia que abrange trabalhos com xerox, arte postal, poesia visual, desenho, pintura, apropriação, colagem e fotografia. Além disso o artista desenvolveu inúmeras performances, intervenções urbanas, instruções, xerofilmes e livros de artista. Com o objetivo de refletir sobre possíveis desdobramentos da arte contemporânea na esfera urbana, são tecidas relações entre algumas de suas proposições artísticas durante as décadas de 70 e 80 e as práticas situacionistas iniciadas na França em meados do século XX, a partir dos escritos de Guy-Ernst Debord e da revista Internacional Situacionista (IS). São apresentados trabalhos realizados por Bruscky, nos quais a cidade e seus ocupantes tem um papel central em sua concepção e realização, um recorte que paralelamente dialoga com alguns termos situacionistas como deriva, desvio e psicogeografia.

Palavras-chave: Paulo Bruscky, cidade, situacionista, intervenção urbana.

\section{ABSTRACT}

Paulo Bruscky is a Brazilian artist recognized internationally for his great intermedia art production that includes works with xerox, mail art, visual poetry, drawing, painting, appropiation, collage and photography. Furthermore the artist developed several performances, urban interventions, instructions, xerofilms and artists' books. With the aiming to reflect about contemporary art and the urban sphere, connections are made between some of his artistic propositions made during the decades of 1970 s and 1980 s and the situationist practices initiated in France in the 2oth century as from the writings of Guy-Ernst Debord and the Situationist International magazine (IS). There are presented works done by Bruscky in which the city and its occupants have a central role in its conception and realization, an approach that at the same time connects with some Situationist terms such as dérive (drift), deviation and psychogeography.

Keywords: Paulo Bruscky, city, situacionist, urban intervention. 


\section{Paulo Bruscky: Intervenções e Deslocamentos de Sentido no Es- paço Urbano}

Introdução

Quando fui preso pela ditadura militar, que desgovernou o Brasil a partir de 1964, vivi involuntariamente isso que disse Duchamp e tomei como epígrafe na prática; quando, mais chocado que surpreso com meu trabalho, um agente federal disse: 'Então se eu arrancar um pedaço desse piso e colocar na parede isso é arte?'. Na época, o piso era vulcapiso. Eu respondi: 'Se você colocar, não. Se eu colocar é que é arte!' Passei perto de apanhar... Paulo Bruscky (FREIRE, 2006, p. 98)

A problemática da arte contemporânea no contexto urbano é recorrente na obra de vários artistas e, historicamente, é marcada por diversos movimentos de vanguarda. Desde os dadaístas e surrealistas, passando pelos situacionistas e o grupo Fluxus, inovadoras e inusitadas proposições deram início à prática de olhar, ocupar e transformar o ambiente citadino. Sob esse panorama abordo proposições do artista intermídia Paulo Bruscky, que problematizam a cidade, seus ocupantes e microuniversos, tecendo algumas relações com as propostas e ações situacionistas em meados do século XX. Artistas, intelectuais e ativistas, os situacionista estavam interessados numa arte que, rompendo os padrões modernos, seria diretamente ligada à cidade e à vida urbana (BERENSTEIN, 2003, p. 18). Ancoravam-se em certos conceitos e discussões que eram veiculados e compartilhados através da revista Internacional Situacionista, que, entre 1958 e 1969, teve 12 números publicados (idem). Alguns desses conceitos serão citados no presente artigo, tais como deriva, desvio e psicogeografia. A fim de facilitar o entrosamento do leitor com a estratégia situacionista transcrevo o trecho da revista IS $n^{\circ} 1$ que faz menção aos termos em questão.

situacionista - 0 que se refere à teoria ou à atividade prática de uma construção de situações. Indivíduo que se dedica a construir situações. Membro da Internacional Situacionista.

psicogeografia - Estudo dos efeitos exatos do meio cartográfico, conscientemente planejado ou não, que agem diretamente sobre o comportamento afetivo dos indivíduos.

(...)

deriva - Modo de comportamento experimental ligado às condições da sociedade urbana: técnica de passagem rápida por ambiências variadas. Diz-se também, mais particularmente, para designar a duração de um exercício contínuo dessa experiência.

(...)

desvio - abreviação da expressão: desvio de elementos estéticos pré-fabricados. Integração de produções artísticas, atuais ou passadas, em uma construção superior do ambiente. Neste sentido, não pode haver pintura ou música situacionista, mas um uso desses recursos. (1958 apud BERENSTEIN, 2003, p. 66)

A deriva e a psicogeografia não correspondem às práticas essencialmente artísticas, porém, pela via experimental e inventiva provocam uma ruptura no modo convencional 


\section{Paulo Bruscky: Intervenções e Deslocamentos de Sentido no Es- paço Urbano}

de apreensão do espaço urbano, proporcionando, assim, novas experiências estéticas e afetivas. A ideia de perambular pela cidade remonta ao conceito de flâneur de Baudelaire em 1863, no texto Le peintre de la vie moderne (A pintura da vida moderna - tradução própria) (BERENSTEIN, 2003, p. 34). Prossegue com o Dadaísmo e suas excursões citadinas a lugares banais, que pouco tempo depois foram desdobradas pelos surrealistas através das experiências de errância pela cidade, e, posteriormente, Walter Benjamin retoma o termo de Baudelaire trabalhando com a ideia de flanar pela cidade como mecanismo de ativação e vivência do espaço urbano (idem).

Segundo Berenstein (2003, p.20), as ideias, procedimentos e práticas urbanas situacionistas poderiam "ainda hoje inspirar novas experiências, interessantes e originais, de apreensão do espaço urbano". A partir da proposição e construção de situações surgiriam novas formas de vivenciar e apropriar-se (ou reapropriar-se) da cidade. Apoiados nos escritos de Guy-Ernest Debord (1931-1994), um dos fundadores da Internacional Situacionista (IS), os situacionistas tinham como principais influências o Dadaísmo e o Surrealismo. 0 meio urbano era o espaço propício de ação e intervenção contra a alienante e desestimulante vida cotidiana na qual os indivíduos estariam mergulhados e a arte surgiria como potencial ferramenta de transformação ao abrir caminho para 0 desvio.

A Internacional Situacionista - grupo de artistas, pensadores e ativistas - lutava contra o espetáculo, a cultura espetacular e a espetacularização em geral, ou seja, contra a não-participação, a alienação e a passividade da sociedade. 0 principal antídoto contra a não-participação ativa dos indivíduos em todos os campos da vida social, principalmente no da cultura (BERENSTEIN, 2003, p. 13).

Sem limitações quanto ao suporte, a obra de Bruscky abarca vídeos, filmes, xerofilmes, performances, poesia visual, projetos de arte postal, fotografias, colagens, pinturas, desenhos, livros de artista, apropriações diversas, instruções e intervenções (urbanas ou não), uma vastidão múltipla e abrangente. Entre as décadas de 70 e 80 realizou inúmeras ações performáticas e interventivas na cidade de Recife, Pernambuco, nas quais a cidade se convertia numa singular galeria de exposição, completamente aberta e acessivel a todos os que perambulavam por ela diariamente. Tentativas, talvez, de investigar as relações entre arte e cotidiano, urbano e público, indivíduo e meio em que está inserido. A maioria dessas ações foram efêmeras e inéditas, pois rompiam completamente com a premissa de obra durável, seu consumo era imediato e "essencialmente avesso à conservação sob a forma de mercadoria" (IS nº 4,1960 apud BERENSTEIN, 2003, p.121). Criaram-se "antimonumentos" (FREIRE, 1997, p. 65): a potência do trabalho residia em sua dissolução no tempo como acontecimento único e pontual, correspondendo a uma temporária interrupção, uma anomalia no ritmo frenético da complexa zona de passagem que constitui a cidade. A partir disso, apresento uma série de trabalhos realizados pelo artista que, carregados de ironia e humor, constantemente questionam o que se considera corriqueiro, revelando muitas vezes o que já foi esquecido ou jamais apreendido. A cidade surge enquanto espaço de experimentação e deriva, a arte como desvio, ambiência provocadora de intervenções e deslocamentos de sentido. 


\section{Paulo Bruscky: Intervenções e Deslocamentos de Sentido no Es- paço Urbano}

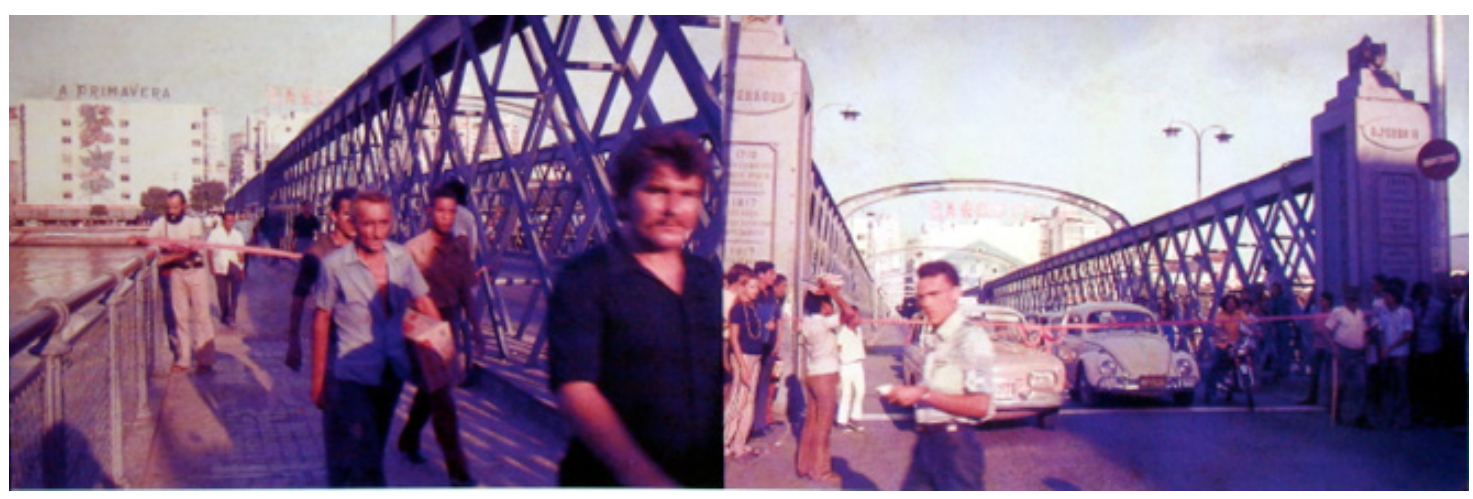

Arte/Pare, 1973.

\section{Arte e Vida}

Paulo Bruscky trabalhou como funcionário público no setor administrativo do Hospital Agamenon Magalhães no Recife e em paralelo desenvolveu intensamente grande parte de sua trajetória artística (FREIRE, 2006, p. 51). Sua mente inventiva explorou incansavelmente os recursos que estavam diariamente à sua volta, muitos deles extremamente inusitados, como a máquina de xerox com a qual desenvolveu os xerofilmes. Sempre reinventando o cotidiano, o artista realizou ações em seu antigo ambiente de trabalho, nas ruas, praças e pontes do Recife, como também durante suas viagens pelo Brasil e no exterior. Grande parte de seu trabalho tem um caráter transitório e informal. Para o artista, não interessava uma obra de aspecto refinado e bem acabado, já que os traços do processo e as relações construídas durante ele é que marcam seu trabalho.

Em Paulo Bruscky - Arte, Arquivo e Utopia (2006, p. 98), Cristina Freire descreve como, em 1981, Bruscky realizou em parceria com o artista Daniel Santiago e com a prefeitura da cidade do Recife o projeto Art-door, no intuito de propor novas maneiras de olhar a cidade e subverter modelos já estabelecidos. Artistas brasileiros e estrangeiros oriundos de 25 países participaram da mostra e fizeram cerca de 111 outdoors espaIhados pelas ruas. Ao apropriarem-se de um meio de comunicação característico da publicidade e subverterem sua função, os artistas abriam campo para que uma inédita experiência estética ocorresse. Houve uma reinvenção na dinâmica local, a paisagem urbana tornou-se algo mais que "depósito" para propagandas e anúncios comerciais. Os passantes tiveram a possibilidade de aprovar (ou não) as obras expostas, ou mesmo de percebê-las (ou não) no ambiente. A exposição livre e não-comercial driblava a lógica convencional do sistema de arte voltado aos museus e galerias. A cidade revelou-se como potencial local expositivo e criativo, como numa fuga de sua definição enquanto ambiente funcional e supostamente não-artístico.

Os artistas criaram a expressão Art-door especialmente para esta exposição, que foi pioneira no Brasil por apropriar-se de outdoors como superfície e da própria cidade como espaço expositivo (FREIRE, 2006, p. 99). 0 arquivo Bruscky e a arte correio foram indispensáveis para a realização da mostra: os artistas participantes foram convidados através de postais, e os trabalhos foram enviados ao Recife através da mesma rede de 


\section{Paulo Bruscky: Intervenções e Deslocamentos de Sentido no Es- paço Urbano}

arte postal internacional, que possui mais de 3000 nomes catalogados (idem). Em 1982 houve a $2^{\mathrm{a}}$ Exposição de Art-door, também em Recife, mas infelizmente não tive acesso a qualquer material mais detalhado sobre. Até mesmo a primeira exposição de 1981 está escassamente documentada com relação a material para pesquisa.

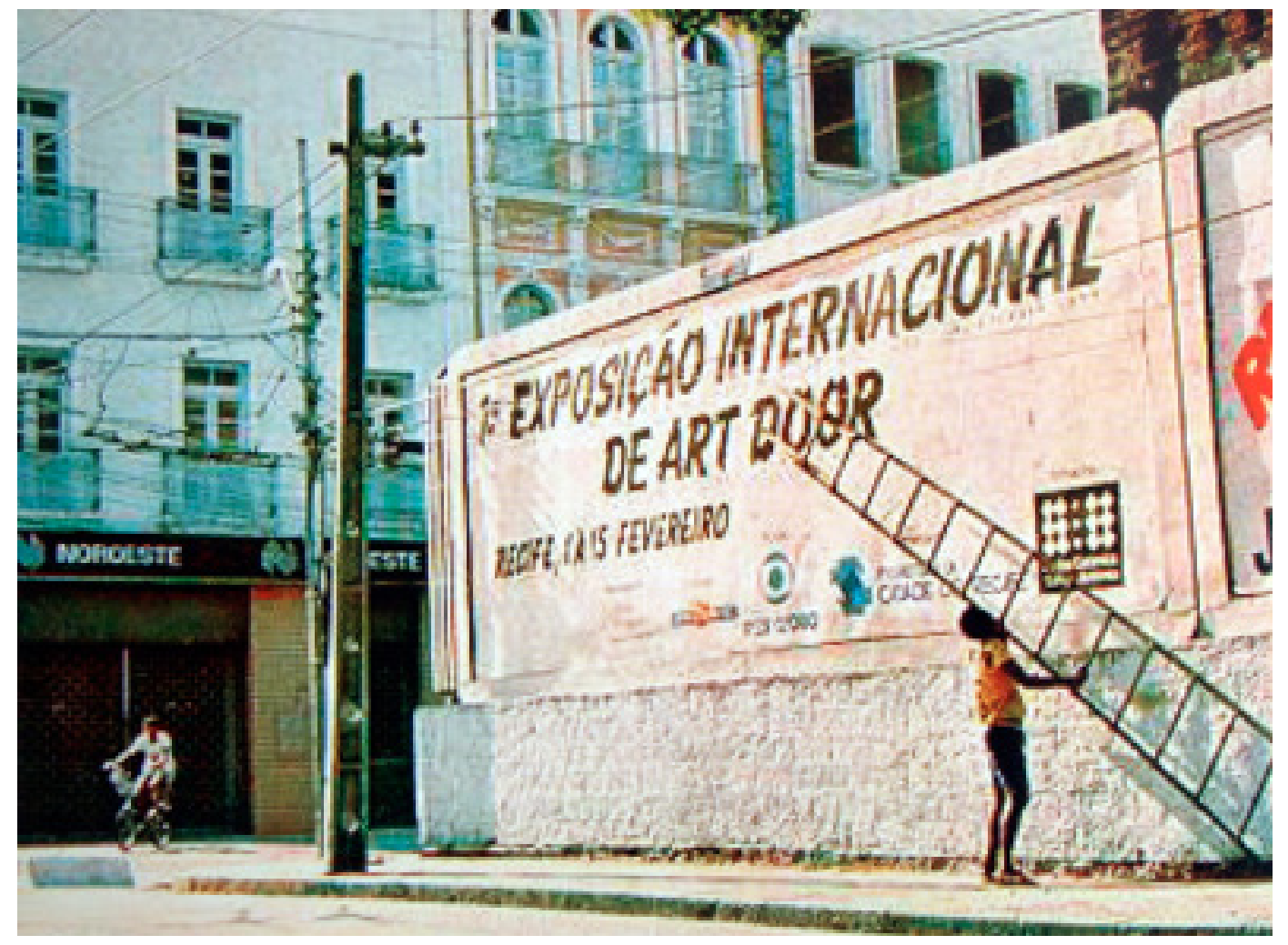

${ }_{1} a$ Exposição Internacional de Art-door, 1981.

Sobre a $1^{\mathrm{a}}$ Exposição Internacional de Art-door os artistas declararam:

$\mathrm{Na}$ art-door, a arte sai das requintadas galerias e dos arcaicos museus e toma forma em cartazes espalhados pela cidade, que é transformada num grande espaço artístico: $3942 \mathrm{~m}^{2}$ de obras de arte em exposição. 0 artista, no juízo final, sendo julgado pela população (o que intimidou a participação de vários artistas, principalmente os pseudomuralistas, os Siqueiros da vida), numa exposição sem fins comerciais, onde a propaganda cede seu lugar para trabalhos das mais variadas técnicas, desde os mais tradicionais regionalistas, até as propostas mais recentes da arte contemporânea (poemas visuais, carimbos, xerox, propostas, etc), com a participação de 286 artistas de 25 países, dá oportunidade aos artistas e ao povo de presenciar 0 que está acontecendo em todo o mundo. Paulo Bruscky e Daniel Santiago (FREIRE, 2006, p. 99)

Para Debord, "a vida cotidiana é a medida de tudo: da realização - ou melhor, da não-realização - das relações humanas; da utilização do tempo vivido; da pesquisa na arte; da política revolucionária" (BERENSTEIN, 2003, p. 145). Diariamente faz-se a escolha entre 


\section{Paulo Bruscky: Intervenções e Deslocamentos de Sentido no Es- paço Urbano}

permanecer parte de uma massa alienada e facilmente manipulável ou não. Pode-se criar, reinventar conceitos, redescobrir o próprio cotidiano, o caminho diário para casa, o local de trabalho, o meio em que se vive pode revelar-se um mistério a ser investigado: viver na cidade com a premissa de reinventá-la, ativá-la de uma maneira inédita. Nesse contexto, Bruscky desvela o espaço urbano como uma complexa rede de caminhos, conexões e possibilidades para as infinitas singularidades que nele se abrigam, infinitas formas de viver e de ver o mundo.

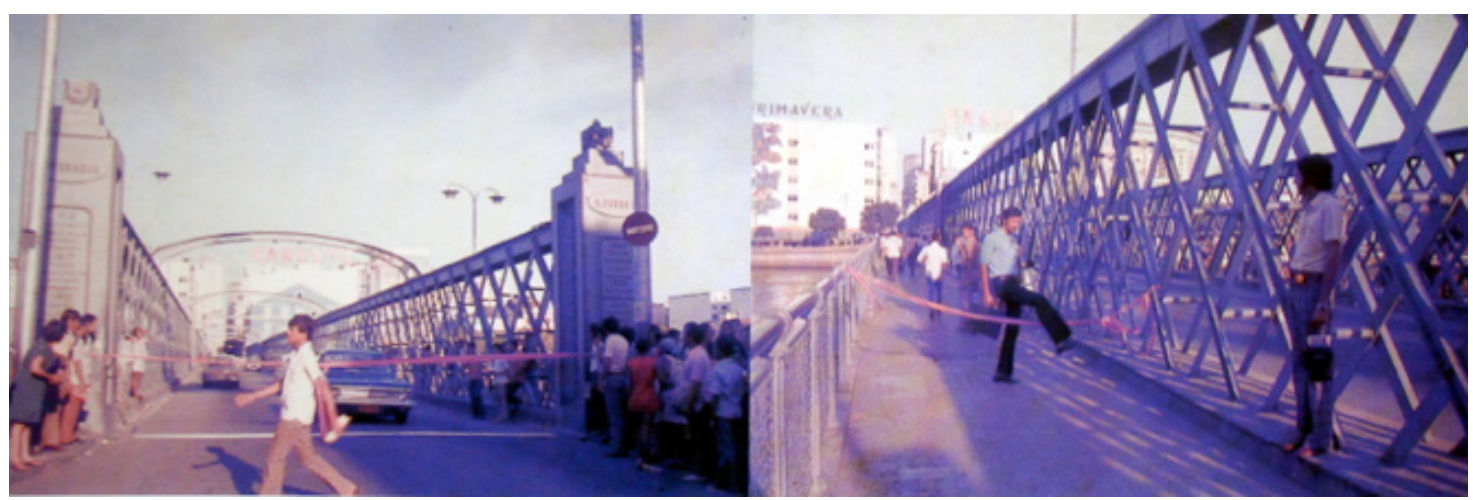

Arte/Pare, 1973.

Em 1973, Paulo Bruscky propôs com Arte/Pare a reinauguração da Ponte da Boa Vista, no centro de Recife, construída em 1633 por Maurício de Nassau (FREIRE, 2006, p. 88). Com uma imensa fita vermelha, o artista "fechou" a ponte. Diante da desconcertante situação, pedestres e carros pararam por cerca de quarenta minutos até que alguém resolveu desamarrar a fita (idem). 0 vídeo que documentou a ação esteve em exposição na $29^{\mathrm{a}}$ Bienal de São Paulo, em 2010. Em Artexpocorponte (1972) as pontes da Boa Vista e Duarte Coelho foram ocupadas pelos participantes da ação que, munidos de cartazes, trocavam sinais ativando e estabelecendo uma comunicação singular: as pontes, sobre o rio Capibaribe, são paralelas o que permitiu a interação dos dois grupos através dos cartazes (idem, p. 87). Propondo novas estratégias de uso e interação para com lugares-comuns do espaço urbano, o artista cria a passagem para a fuga, para a investigação de novas abordagens da arte, do cotidiano, da vida.

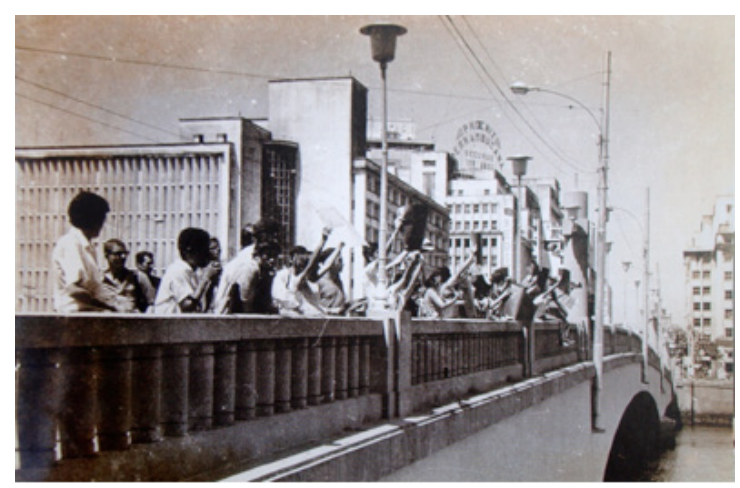

Artexpocorponte, 1972. 


\section{Paulo Bruscky: Intervenções e Deslocamentos de Sentido no Es- paço Urbano}

Bruscky explora o lúdico e o inesperado no espaço urbano coletivo tomando a realidade como um imprevisível jogo a ser inventado e reinventado constantemente, onde criatividade e acaso se complementam. Em Artemcágado(1972), novamente em parceria com Daniel Santiago, o artista propõe uma exposição/concurso de cágados na Pracinha do Diário, centro de Recife, onde uma banca julgadora elegeria o cágado ornamentado de forma mais original (FREIRE, 2006, p. 79). Percebe-se uma inusitada alusão à característica cultura carnavalesca da cidade em questão, um desfile de cágados fantasiados é uma proposição bastante inusitada de carnaval fora de época. A utilização do espaço público expande-se para a criação de inéditas experimentações coletivas.
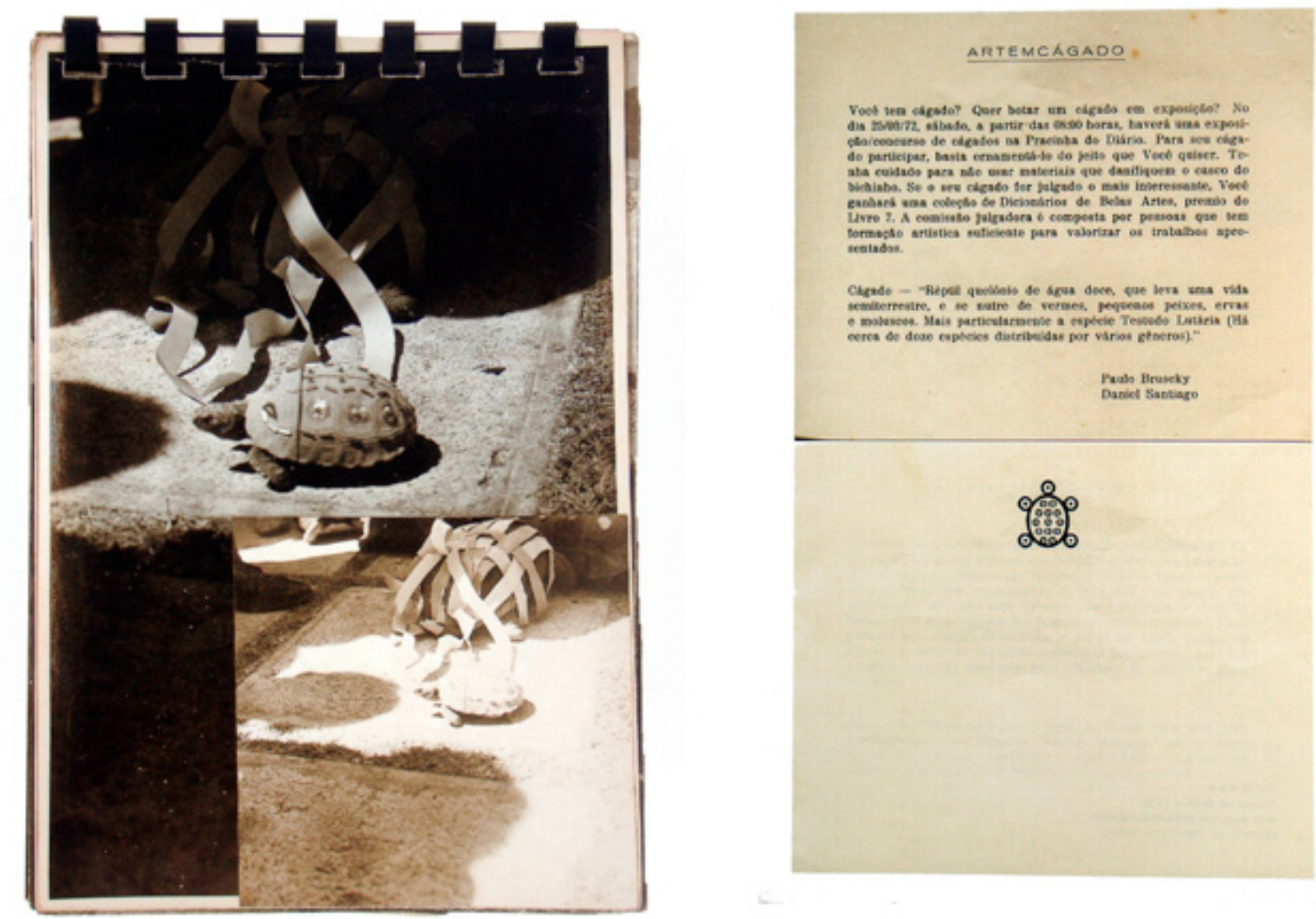

Convite para Artemcágado, 1972

Seguindo a mesma linha lúdica e descontraída, Bruscky e Daniel Santiago realizam Artempé (1972), uma convocatória para uma exposição onde cada convidado deveria comparecer com sapatos de pares diferentes (FREIRE, 2006, p. 79). Interessava aos artistas provocar o estranhamento do cotidiano a partir da subversão do uso do objeto e revelar "a ironia resultante de seu desuso e de sua inutilidade" (idem, p. 32). 0 problema contextualizado aqui vai além da ação corriqueira diária, aborda o cotidiano como um todo que absorve completamente o indivíduo, transformando-o num ser autômato, tirando dele as rédeas de sua própria existência e lançando-o num fluxo desenfreado de afazeres e formalidades. Para Debord, "a enorme pobreza da organização consciente, a falta de criatividade das pessoas na vida cotidiana expressam a necessidade fundamental de inconsciência e de mistificação numa sociedade exploradora, numa sociedade da alienação" (BERENSTEIN, 2003, p. 146). A fragmentação do tempo e seu consequente preen- 


\section{Paulo Bruscky: Intervenções e Deslocamentos de Sentido no Es- paço Urbano}

chimento por diversas atividades vazias de sentido tornam o indivíduo distanciado de suas verdadeiras vontades e desejos. "A vida cotidiana torna-se assim a vida privada, domínio da separação e do espetáculo" (idem). Reinventando esse mesmo conjunto diário de atividades, reformulando seu conteúdo, o cotidiano ganha faces múltiplas, imprevisíveis e orgânicas. As intervenções de Bruscky demonstram como é possível despertar diante do fluxo caótico urbano, como pode-se vivenciá-lo questionando-o e transformando-0.
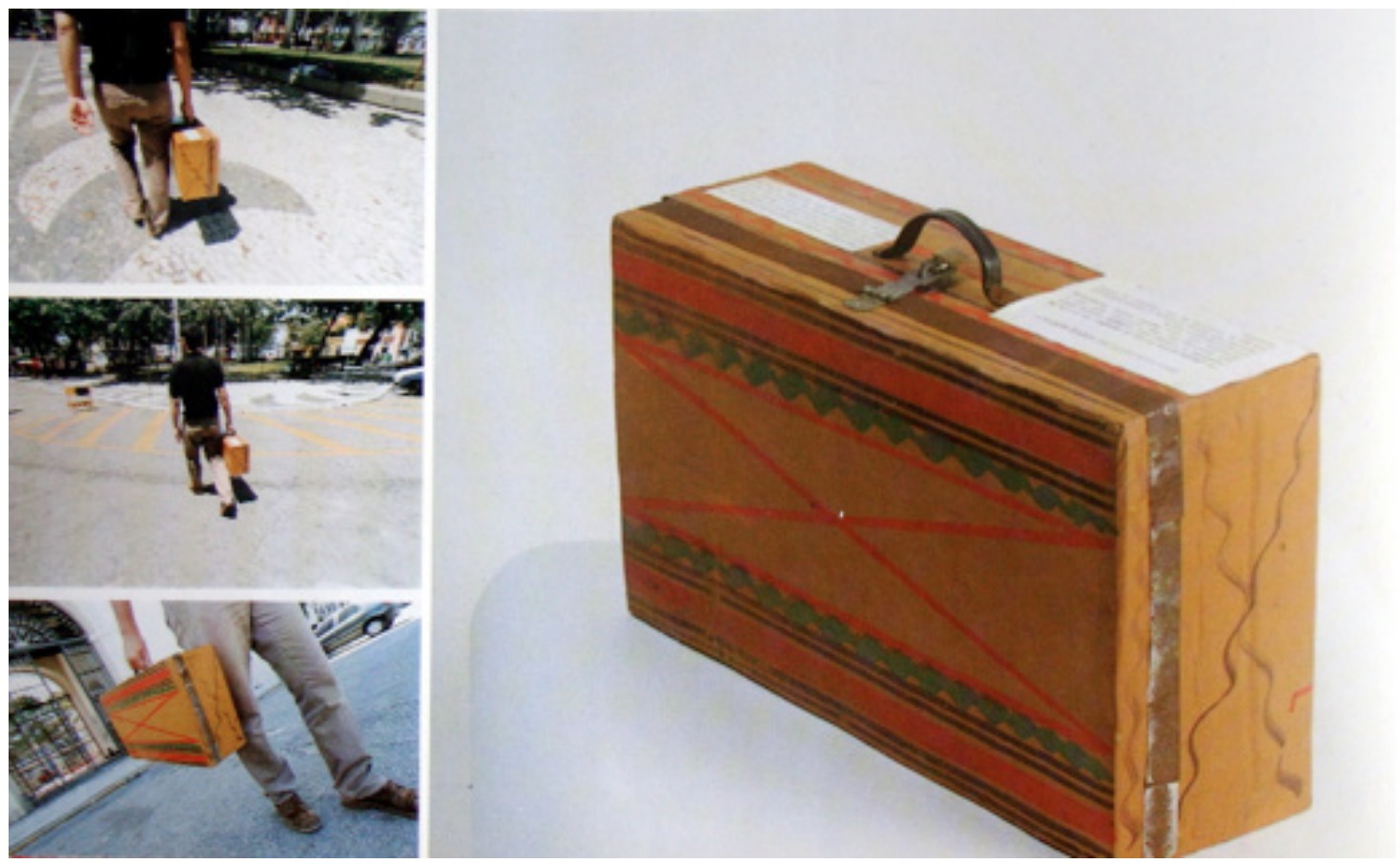

Mala, 1974.

No I Salão de Arte Global de Pernambuco, em 1974, Bruscky realizou o projeto Mala, que consistia numa mala abandonada no local expositivo para a livre manipulação dos visitantes (FREIRE, 2006, p. 80). 0 objeto, como esperado pelo artista, saiu dos limites físicos da exposição e ganhou as ruas, sendo transportado aleatoriamente no espaço urbano. A continuidade do projeto acontecia casualmente na medida em que os indivíduos escolhiam ou não interagir com o objeto. Em 20010 projeto foi realizado mais uma vez. A perambulação pelas ruas da cidade é uma ação recorrente em diversos trabalhos do artista. 0 andar descompromissado seria um potencial ponto de partida para a criação de novas maneiras de vivenciar a cidade, como um retorno ao nível "o" de reconhecimento, experimentar um novo ângulo, outra maneira de olhar, algo já visto, já conhecido. "A deriva seria uma apropriação do espaço urbano pelo pedestre através da ação do andar sem rumo" (BERENSTEIN, 2003, p. 22). Numa retomada dos elementos diluídos no cotidiano, a surpresa e a descoberta tornam-se parte de um jogo inédito e subversivo: um outro modo de caminhar, um outro modo de ver, um espaço para o desvio e para a fuga, re-criando caminhos e trajetórias.

Ao tomar o conhecido como possível plataforma para o imprevisto, o indivíduo coloca- 


\title{
Paulo Bruscky: Intervenções e Deslocamentos de Sentido no Es- paço Urbano
}

-se aberto a novas e inesperadas experiências. Como um passageiro de primeira viagem, pequenos detalhes, antes despercebidos, são capturados, a cidade, tão conhecida e banalizada, se revela surpreendente e peculiar. Buscando essa possível re-descoberta de sua cidade natal, no início da década de 1970, Bruscky propõe a cidade de Recife como uma grande e inédita exposição coletiva (FREIRE, 2006, p. 77). A cidade é tomada "como a própria obra de arte e não como mero suporte para a intervenção artística" (idem). Apropriando-se de locais centrais da paisagem urbana, o artista "exibiu" obras como A Avenida Guararapes à noite, 0 rio Capibaribe visto do $5^{\circ}$ andar do Edifício Teresa Cristina e A madrugada na Avenida Conde da Boa Vista (idem). Aqui "realidade e representação se confundem, a arte se realiza num tempo-espaço real" no "campo da experiência da perambulação citadina" (FREIRE, 1997, p. 60). Procedimento que, se por um lado revela a cegueira diária, por outro reconecta o indivíduo aos lugares e detalhes que the são afetivos, que se vê tal qual o psicogeógrafo situacionista.

\begin{abstract}
A psicogeografia estudava o ambiente urbano, sobretudo os espaços públicos, através das derivas e tentava mapear os diversos comportamentos afetivos diante dessa ação básica do caminhar na cidade. (...) A psicogeografia seria então uma geografia afetiva, subjetiva, que buscava cartografar as diferentes ambiências psíquicas provocadas basicamente pelas deambulações urbanas que eram as derivas situacionistas. (BERENSTEIN, 2003, p. 22)
\end{abstract}

A instrução Intervenções Urbanas / exercícios para a cidade $n^{\circ} 1$ - Silhuetas (1980) propunha um percurso pelo centro da capital pernambucana (FREIRE, 2006, p. 81). 0 participante que se propusesse a seguir de livre e espontânea vontade o conjunto de passos listados realizaria a obra. Dessa forma, "o campo de ação seria portanto a rede urbana, expressão natural da criatividade coletiva, capaz de compreender as forças criadoras que se libertam com o declínio de uma cultura baseada no individualismo" (BERENSTEIN, 2003, p. 114). Em trabalhos como esse, Bruscky dialoga com as abordagens situacionistas, também com as proposições do grupo Fluxus, do qual era integrante e representante no Brasil.

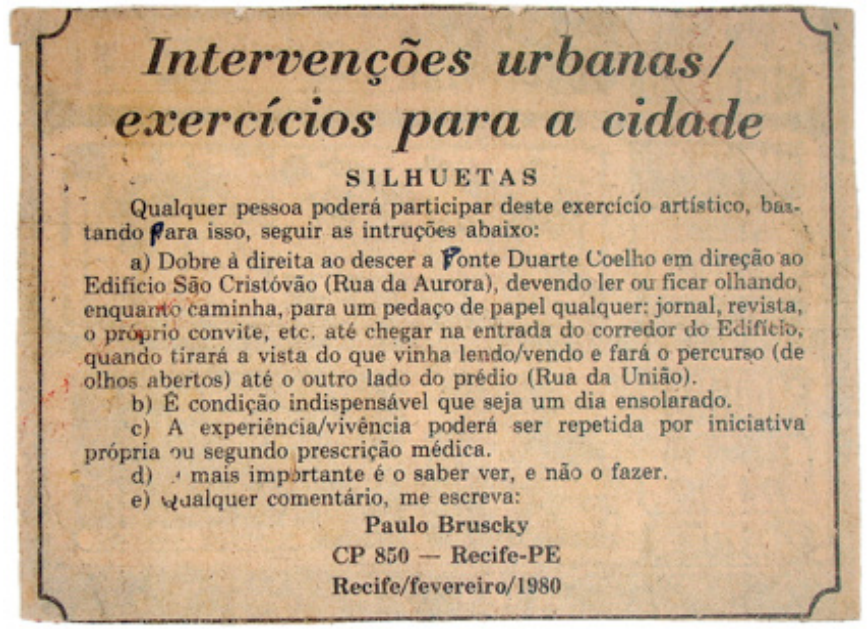

Intervenções Urbanas / exercícios para a cidade $n^{\circ} 1$ - Silhuetas, 1980. 


\section{Paulo Bruscky: Intervenções e Deslocamentos de Sentido no Es- paço Urbano}

\section{Conclusão}

Apresentando sucintamente esses projetos artísticos, elucido a importância da obra de Paulo Bruscky, este artista nacional de projeção internacional. 0 fato de terem ocorrido há mais de duas décadas os torna ainda mais pertinentes para o contexto da arte contemporânea atual, considerando, além disso, que constituem apenas um recorte da intensa e diversa produção do artista. Diante da amplitude de tal trajetória, a bibliografia existente se revela restrita e, de certo modo, desconhecida, evidenciando a importância e necessidade de novas incursões neste campo tão vasto e ainda pouco investigado que é a trajetória de artistas brasileiros fora do eixo Rio-São Paulo, cuja produção se deu numa época de efervescência política e de atuação das vanguardas.

Mergulhar no extenso repertório de obras desenvolvidas por Paulo Bruscky já constitui por si só permitir-se a uma deriva de ideias, experiências e desdobramentos. A partir de proposições inusitadas, 0 artista subverte a funcionalidade imposta pelo cotidiano a um determinado lugar, a um determinado conjunto de pessoas desviando-os para breves momentos lúdicos, críticos, insólitos. Num período histórico marcado por grandes esforços das autoridades nacionais para manter a ordem estabelecida, Bruscky insistiu em frágeis, porém efetivas, fissuras para provocar a transformação e reconfiguração do entorno, ainda que temporariamente. Nessa perspectiva, as investigações da arte no meio urbano, da arte e política, arte e público estão longe de um esgotamento, nota-se a quantidade de ações que surgem em diversas cidades brasileiras, artistas, coletivos, ativistas e pessoas em geral movem-se numa consciência mútua da necessidade de se apropriar, de ocupar, de ativar os espaços públicos. Bruscky mostra como, com tão pouco e de forma simples e sincera, é possível alterar significativamente o contexto em que se está inserido, deixando a impressão de que pequenas tentativas de alteração do meio em que se vive facilmente podem ganhar proporções sem limites. 

paço Urbano

\section{Referências Bibliográficas}

> BERENSTEIN, Paola Jacques (org.) - Apologia da Deriva - Escritos situacionistas sobre a cidade/ Internacional Situacionista, Rio de Janeiro: Casa da Palavra, 2003.

> FREIRE, Cristina. Além dos Mapas - Os monumentos no imaginário urbano contemporâneo, São Paulo: SESC: Annablume, 1997.

> FREIRE, Cristina. Paulo Bruscky - Arte, Arquivo e Utopia, Companhia Editora de Pernambuco, São Paulo, 2006.

> Internacional Situacionista número 1, junho de 1958; número 4, junho de 1960.

\section{Imagens}

> FREIRE, C. Paulo Bruscky - Arte, Arquivo e Utopia, Companhia Editora de Pernambuco, São Paulo, 2006, p.78, 80, 81, 87, 88, 98.

Pamella Emília Queiroz Araújo, Bacharel em Artes Visuais pela Universidade do Estado de Santa Catarina (2011) vive e trabalha em Recife. Ilustradora e artista visual, suas pesquisas envolvem principalmente livro de artista, caderno de processo, diário gráfico, aquarela e gravura.

pamella.eqa@gmail.com 